\title{
Laudatio
}

\section{Zum Rücktritt von Professor Lukas Kappenberger, Lausanne}

Zum Ende des Sommersemesters 2008 ist Prof. Lukas Kappenberger, Ordinarius für Kardiologie an der Universität und am Centre Hospitalier Universitaire (CHUV) Lausanne, nach über 20-jähriger erfolgreicher Tätigkeit zurückgetreten.

Die Kardiologie der Schweiz verdankt Prof. Lukas Kappenberger viel, und es ist uns eine Freude, diesen Dank für viele seiner Freunde und Weggefährten auszudrücken.

Dank gebührt Lukas Kappenberger für seinen unermüdlichen, über 20-jährigen Einsatz für die universitäre Kardiologie am CHUV, wo er vor allem auf dem Gebiet der Elektrophysiologie und Cardiac-Device-Therapie bahnbrechende Erfolge verzeichnen und Lausanne zu einem internationalen «Center of Excellence» machen konnte, obwohl er dazu immer wieder lokale Steine aus dem Weg räumen oder überspringen musste.

Speziell stolz darf er dabei auf sein Lausanner Herzmodell sein, mit dem er grundlegend neue Erkenntnisse über elektromechanische Zusammenhänge erarbeiten konnte; ein Projekt, das ihn mit seiner «Lausanne Heart Group» auch nach seinem Rücktritt noch weiter intensiv beschäftigen wird.

Dank gebührt Lukas Kappenberger auch für sein grosses Engagement in der Schweizerischen Gesellschaft für Kardiologie, wo er der wesentliche Motor zur Erlangung des eigenständigen FMH-Titels «Kardiologie» war, und für sein

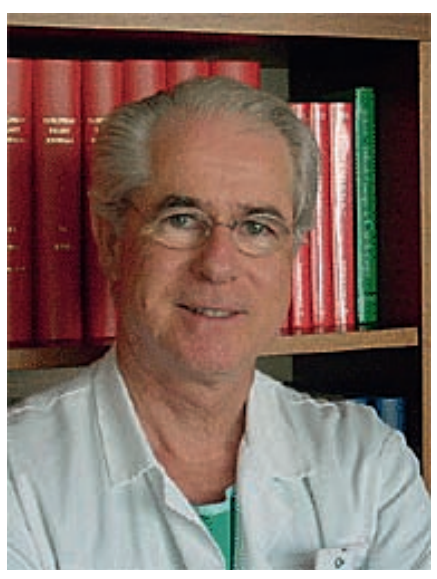

Lukas Kappenberger

langjähriges Engagement als Mitglied und Vizepräsident der Schweizerischen Herzstiftung, in der er Lausanne auch über viele Jahre im wissenschaftlichen Ausschuss vertrat.

Danken dürfen wir Lukas auch ganz speziell für seine Freundschaft, Offenheit und Geselligkeit. Wir hoffen, dass wir dies weiterhin mit ihm teilen können, jetzt, wo er mehr Zeit zur Verfügung haben wird, dies in seiner «Sonnenblume» in Gstaad, im eigenen Flugzeug hoch über den Bergspitzen, im geliebten Tessin oder mit dem Motorboot auf «hoher See» zusammen mit seiner wachsenden Familie zu geniessen.

Lukas, den «Professeur honoraire» hast Du Dir nicht nur von der Universität Lausanne, sondern auch aus Sicht der Schweizer Kardiologie «summa cum laude» verdient!

Matthias Pfisterer, Basel, und Thomas F. Lüscher, Zürich 